\title{
CONTRIBUIÇÕES DA PSICOLOGIA HISTÓRICO-CULTURAL NA APROPRIAÇÃO DA LINGUAGEM ESCRITA NA INFÂNCIA
}

\author{
Géssica Nayara Alves Magalhãesi $₫ 0000-0001-9383-1521$ \\ Centro Universitário UniFatecie \\ Micaela Brito Solerai $₫ 0000-0001-5927-2551$ \\ Centro Universitário UniFatecie \\ Denise Kloeckner Sbardelotto ${ }^{\mathrm{iii}}$ 0000-0001-5693-4986 \\ Centro Universitário UniFatecie
}

Resumo: Esta pesquisa fundamenta-se a partir dos pressupostos teóricos da Psicologia Histórico-Cultural, desenvolvida por L. S. Vigotski, A. R. Luria e A. Leontiev e se ampara também no método de pesquisa materialista histórico-dialético, elaborado por Karl Marx (1818-1883). Tendo em vista a linguagem como um instrumento desenvolvido pelo gênero humano, esta pesquisa objetiva compreender o papel que desempenha a apropriação da linguagem escrita no desenvolvimento do psiquismo mediante uma metodologia bibliográfica de cunho teórico-analítico e de método clínico de entrevistas. Através de atividades relacionadas à escrita infantil adequada à idade, analisamos o nível de desenvolvimento na linguagem em alunos de 06 a 10 anos, buscando observar e estimular a Zona de Desenvolvimento Proximal (ZDP). Concluímos que os alunos investigados alcançaram os objetivos de escrita por meio da mediação das pesquisadoras durante a pesquisa, e a sala de aula para eles, além do significado internalizado, tem um sentido pessoal positivo.

Palavras-chave: Aprendizagem. Zona de Desenvolvimento Proximal. Periodização.

\section{CONTRIBUTIONS OF HISTORICAL-CULTURAL PSYCHOLOGY IN THE APPROPRIATION OF WRITING LANGUAGE IN CHILDHOOD}

\begin{abstract}
This research is based on theoretical assumptions of sociocultural theory, developed by L. S. Vygotsky, A. R. Luria and A. Leontyev; furthermore it is also built on Karl Marx's (18181883) Dialectical and Historical Materialism method. Considering language as an instrument developed by mankind, this research aims to understand the role that the appropriation of writing plays in the development of the psyche through a bibliographical methodology with a theoretical and analytical nature and a clinical
\end{abstract}

interview method. Through age-appropriate activities related to children's writing, we analyzed the level of language development in aged 6 to 10 years old students, attempting to observe and stimulate the Zone of Proximal Development (ZPD). We conclude that the investigated students achieved the writing goals through the mediation of the researchers during the research, and besides, the classroom in addition to internalized meaning, has a positive personal sense for them.

Keywords: Learning. Proximal Development Zone. Periodization. 


\section{Introdução}

A importância dessa pesquisa é de contribuir para a aprendizagem e desenvolvimento acadêmico e possíveis contribuições no campo da psicologia e da educação. Essa contribuição está intimamente relacionada à concepção de homem, enquanto ser histórico e social proposto por Marx (1818-1883) e Engels (1820-1895) assumida no presente projeto.

Busca-se por meio de uma análise teórica respaldada por um método crítico, a superação do determinismo biológico para a compreensão histórica e social do desenvolvimento do psiquismo humano que está em constante construção através das mediações repassadas historicamente pela humanidade, que permitem a humanização desse indivíduo através da internalização e socialização com a cultura, por meio dos signos associados à Pedagogia Histórico-Crítica de Saviani.

Esse trabalho será realizado abordando a teoria de Lev Semyonovich Vigotski (1991) em relação ao conceito de Zona de Desenvolvimento Proximal - ZDP, e de Alexis Nikolaevich Leontiev (2010) em sua concepção sobre atividade e Daniil Borisovich Elkonin que elaborou a periodização do desenvolvimento psíquico. A pesquisa se respaldará na época da infância e no período da idade escolar (6 a 10 anos), que tem como atividade dominante a atividade de estudo na esfera intelectual-cognitivo que relaciona a criança e o objeto social, focando no problema da dificuldade de aprendizagem dessas crianças e o que elas são capazes de fazer através da mediação, utilizando atividades que expõem a capacidade abstrata e concreta delas.

A partir disso será analisado o processo de apropriação da linguagem e escrita, considerando que é um complexo sistema simbólico que gradualmente se desenvolve, e consequentemente, a linguagem escrita vai se desenvolver em função da linguagem falada como destacou a autora Coelho (2011), que inicialmente, funciona como elo mediador entre a fala e a escrita, e só deixa de ter esse papel quando a criança assume por inteiro a escrita em um processo discursivo, onde possibilita a compreensão da escrita dos outros. Além disso, será destacado a gênese e transformação da linguagem escrita ao longo da formação escolar infantil e investigar as potencialidades da leitura e escrita infantil na aquisição da linguagem e estimulação da ZDP refletindo a periodização. 


\section{Referencial teórico}

\subsection{Aquisição da linguagem escrita do desenvolvimento infantil}

2.1.1 Psiquismo humano: dialética, desenvolvimento e aprendizagem

Ao ser adotado o materialismo histórico-dialético como método de pesquisa, é possível compreender a concepção de homem e de mundo, partindo do pressuposto que o conhecimento é um processo complexo, e que através dos instrumentos, signos e dos meios sociais se constituem ao serem internalizados.

Primeiramente, precisa ser destacado o significado de signos e instrumentos para melhor compreensão desse contexto, diante disso, o signo é uma constituição de atividade interna dirigida para o controle do próprio sujeito e a dominação das funções superiores, e os instrumentos seriam as ferramentas materiais, ou seja, o externo, para o controle da natureza.

Vigotski foi o primeiro a aplicar o materialismo histórico-dialético à ciência psicologia, esse método possibilitou entender que os fenômenos psíquicos têm origens sociais, e para os indivíduos se apropriarem destas produções, é necessário fazê-lo mediado, direta ou indiretamente, por outros homens, ou seja, é por meio da aprendizagem que ocorre na relação com os outros indivíduos que as apropriações se realizam (VIGOTSKI, 1991).

Os signos e os instrumentos são criados pela sociedade ao longo da história humana e mudam a forma social e o nível de desenvolvimento cultural dos homens. Todo este processo de internalização do universo simbólico proporciona transformações comportamentais no desenvolvimento individual que tem sua raiz na sociedade e na cultura que está inserido.

O desenvolvimento humano não se trata de um processo natural. Não é a natureza que explica as transformações qualitativas no psiquismo humano. E também não é a natureza que delimita os períodos ou estágios do desenvolvimento psíquico (PASQUALINI, 2016). O desenvolvimento infantil ocorre dialeticamente, a nível social, incluindo avanços, recuos e crises em cada período de desenvolvimento, partindo do mais complexo para o mais simples. As funções superiores originam-se das relações entre os indivíduos, assim, quando internalizado traz significado para as ações, possibilitando a capacidade do homem de criar e empregar signos formando externamente conexões do cérebro. 


\title{
2.1.2 Escola e Zonas de Desenvolvimento
}

À luz da teoria de Vigotski compreende-se o desenvolvimento além do que ele chamou de Nível de Desenvolvimento Real, que significa o estágio que a criança se encontra em sua aprendizagem, no qual se refere às funções mentais da criança como resultado de certos ciclos de desenvolvimento já completados, e sendo assim consegue realizar sozinha. Da mesma forma, o Desenvolvimento Proximal, refere-se à distância entre o que a criança já sabe fazer e o que ela é capaz de fazer com a mediação de alguém, chamado de Nível de Desenvolvimento Potencial, ou seja, o que poderá alcançar a partir de mediações exteriores. Então, a Zona de Desenvolvimento Proximal hoje será o Nível de Desenvolvimento Real amanhã (OLIVEIRA, 2009).

A interação social é fundamental, ainda mais para a formação das funções psicológicas superiores, portanto a priori desses dois níveis já mencionados acima, faz com que o sujeito desenvolva a Zona de Desenvolvimento Proximal - ZDP, que é a distância entre o nível de desenvolvimento real e o nível de desenvolvimento potencial, ou seja, o caminho que a criança percorrerá para atingir o desenvolvimento real. Oliveira elucida:

\begin{abstract}
A zona de desenvolvimento proximal é, pois, um domínio psicológico em constante transformação: aquilo que uma criança é capaz de fazer com a ajuda de alguém hoje, ela conseguirá fazer sozinha amanhã. É como se o processo de desenvolvimento progredisse mais lentamente que o processo de aprendizado; o aprendizado desperta processos de desenvolvimento que, aos poucos, vão tornando-se parte das funções psicológicas consolidadas do indivíduo (OLIVEIRA, 2009, p. 60).
\end{abstract}

O processo psíquico se caracteriza por mudanças qualitativas, apesar disso nem toda aprendizagem promove desenvolvimento, como diz Vigotski (1991), mas ela bem sistematizada possibilita desenvolvimento, é pelo aprendizado que a criança vai desenvolvendo e para que ocorra o desenvolvimento humano depende da ZDP, das mediações que terá, pois a associação entre pensamento e linguagem é atribuída à necessidade de intercambio dos indivíduos durante o trabalho (OLIVEIRA, 2009).

Em paralelo a isso, Saviani (2012), contribuiu, afirmando que ao requalificar as funções psíquicas, a aprendizagem escolar colabora para a formação de conceitos, edificando a consciência qualitativamente, já que a escola fornece o saber sistematizado e tem função crucial na socialização e transmissão do conhecimento construído historicamente pela humanidade. 
Abordando sobre essa ligação do psiquismo com o ensino escolar, é importante salientar que a escola também é um processo histórico-social que forma sujeitos históricos com o intuito de impulsionar a sua criticidade enquanto cidadão para lutar contra o status quo, justamente por estar intimamente ligada com o desenvolvimento das funções superiores (SAVIANI, 2012).

Considerando essa dialética, a atividade humana é internalizada e a consciência humana se forma a partir de signos e instrumentos construídos pela cultura que são internalizadas, tornando-se instrumentos internos e subjetivos do indivíduo, assim, é por meio das palavras que o pensamento passa a existir, sendo que desde a fala o sujeito utiliza como forma de solucionar problemas e somado ao pensamento possibilita comunicação entre as pessoas.

\subsubsection{Linguagem escrita}

Para analisar a linguagem escrita é essencial iniciar falando sobre a relação que a escrita estabelece com o processo discursivo, ou seja, o desenvolvimento da linguagem falada para a escrita. Isso ocorre quando a criança sente necessidade de que as outras pessoas compreendam através da escrita o que quer comunicar e também a necessidade de entender o que o outro escreve. Assim, é a própria linguagem falada que media a aquisição da linguagem escrita (COELHO, 2011).

A aquisição da linguagem escrita é um processo culturalmente construído e é parte de uma sociedade letrada, no qual a criança tem acesso aos diferentes usos da linguagem durante seu desenvolvimento. Para compreender a criança precisa entender primeiramente que "os signos não tem significado entre si, mas representam outra realidade" (OLIVEIRA, 2009, p. $68)$.

A linguagem escrita começa desde a linguagem oral, que serve como suporte para aprendizados posteriores, partindo dessa fase pré-linguística, onde a criança se comunica e manipula objetos. Após isso, o objeto começa a ter significado, o que leva às generalizações, aproximando a função social desses objetos. Na escola, o professor desenvolve seu papel trazendo sentido às atividades propostas para dominar a escrita (MARSIGLIA, SAVIANI, 2017). Nesse contexto, após experimentos realizados com crianças de diferentes idades Luria concluiu que: 
Nossos experimentos garantem a afirmação de que o desenvolvimento da escrita na criança prossegue ao longo de um caminho que podemos descrever como a transformação de um rabisco não diferenciado para um signo diferenciado. Linhas e rabiscos são substituídos por figuras e imagens, e estas dão lugar a signos. Nessa sequência de acontecimentos está todo o caminho do desenvolvimento da escrita, tanto na história da civilização como no desenvolvimento da criança (LURIA, 2010, p. 161).

A escrita é um instrumento e dá suporte para a memória, ideias e conceitos. Inicialmente a escrita da criança é mecânica: ela imita o formato da escrita dos adultos, sem significados, são apenas rabiscos - por isso ainda não servem para auxiliar a memorização.

Depois, a escrita tem marcas topográficas: os rabiscos distribuídos pelo papel ainda não são signos, mas já é possível auxiliar na recuperação da informação. Há ainda uma terceira fase que se refere a representações pictográficas: aparecem desenhos utilizados em forma de escrita, dando significado as palavras por intermédio dos desenhos, que são utilizados como instrumentos e se transformam em signos, pois tem a criança tem conhecimento de sua natureza (OLIVEIRA, 2016).

Realizada as generalizações complexas, a criança entra na fase da escrita simbólica, na qual ocorre o uso exclusivo do sistema alfabético, prosseguindo com a escrita. Através da posse de sua escrita individual acontece a apropriação do conhecimento historicamente produzido pela humanidade (OLIVEIRA, 2016).

Então, chega-se a fase da consolidação da alfabetização, entre os seis e dez anos de idade, que tem como atividade dominante a atividade de estudo: é nesse momento a apropriação da escrita, tendo como elemento crucial o conhecimento. Não basta então a ludicidade e reprodução de ações, mas se torna ímpar conhecer os saberes acumulados por meio da sistematização dos conteúdos, e para isso é importante um trabalho do docente adequado à necessidade do educando para avançar em sua aprendizagem e aquisição de conhecimento (MARSIGLIA, SAVIANI, 2017).

\section{Atividade e periodização histórico-dialética do desenvolvimento psíquico}

O mundo e a criança têm uma relação de um vínculo real e através disso o psiquismo se desenvolve e atua sobre os outros e sobre o contexto em que está inserido. Essa relação foi denominada por Leontiev (2010) por “atividade". É justamente a "atividade" que liga o sujeito ao mundo e, portanto, para compreender o desenvolvimento psíquico torna-se 
importante analisar a "atividade" da criança. Mas enfim, o que é a atividade tanto abordada por Leontiev?

Por atividade, designamos os processos psicologicamente caracterizados por aquilo a que o processo, como um todo, se dirige (seu objeto), coincidindo sempre com o objetivo que estimula o sujeito que estimula o sujeito a executar esta atividade, isto é, o motivo (LEONTIEV, 2010, p. 68).

Fundamentalmente, a atividade regula a ação, ela é a mola propulsora do desenvolvimento, entretanto, nem toda ação pode ser denominada de atividade, apenas o que é internalizado na mediação entre a criança e o mundo. Toda atividade é dirigida por motivos que devem ser alcançados, ou seja, ela não é regulada biologicamente, é a necessidade da cultura que está inserida no contexto social que fomenta a realização de tais atividades, e os motivos surgem embasados nessas necessidades que impulsionam posteriormente a atividade. Os motivos não ficarão estagnados apenas em uma atividade, mas modificam-se conforme o desenvolvimento.

Sendo assim, a atividade é movida por uma intencionalidade e busca responder uma necessidade. Não é tudo o que o indivíduo faz que pode ser chamado de atividade, mas para que seja satisfeita, ela precisa de um objeto que a satisfaça, e quando a necessidade encontra sua determinação no objeto, esse objeto torna-se motivo da atividade e esse motivo é o que impulsiona o homem a agir. Mais interessante ainda é que por trás de um motivo, sempre terá outra necessidade (TULESKI, EIDT, 2016).

Para realizar uma atividade precisa-se de processos internos e externos. O externo é chamado de "ação", a ação é um processo cujo motivo não coincide com seu objetivo, mas reside na atividade da qual ele faz parte. Em uma atividade são desempenhadas várias ações, que permitem a satisfação da necessidade desencadeadora da atividade. Depois disso, considera-se o termo "operação", que seriam as diversas formas que tem para realizar determinada atividade.

Relacionado a isso, é de suma importância destacar que algumas atividades têm papel mais decisivo que outras no desenvolvimento psicológico e em cada período do desenvolvimento uma atividade é a dominante. Como afirma Pasqualini:

A atividade dominante reorganiza e forma processos psíquicos, gera novos tipos de atividade e dela dependem as principais mudanças psicológicas que caracterizam o período (LEONTIEV, 2001b). Em última instancia, podemos 
dizer que em cada período do desenvolvimento uma atividade diferente guia o desenvolvimento psíquico (PASQUALINI, 2016, p. 77).

A atividade é uma mediação na relação dialética entre indivíduo e sociedade, desse modo, "a atividade principal é a atividade da qual dependem, de forma íntima, as principais mudanças psicológicas na personalidade infantil, observadas em certo período de desenvolvimento" (LEONTIEV, 2010, p. 64). É essa mudança de atividade principal também chamada de dominante - que marca o início de um novo período no desenvolvimento, que permitem um salto qualitativo e consequentemente uma mudança na atividade social e reestruturação da consciência, o indivíduo modifica o lugar que ocupa nas relações devido às novas tarefas do seu contexto, afetando também o desenvolvimento da periodização, pois as atividades dominantes são superadas na transição a um novo período, servindo de base à nova atividade dominante (TULESKI, EIDT, 2016).

Aprofundando essa temática, o psicólogo soviético Elkonin, elaborou uma teoria da periodização do desenvolvimento psíquico à luz da concepção histórico-cultural. Tem como suporte três épocas: primeira infância, infância e adolescência. Sendo que cada época dessas tem dois períodos. A primeira infância contém os períodos "primeiro ano de vida" e "primeira infância"; a infância contém o período "idade-pré-escolar" e "idade escolar" e na época adolescência faz parte os períodos "adolescência inicial" e "adolescência". Relacionando esse conceito ao de atividade, é importante destacar que a mudança do conteúdo da atividade que se produz ao longo do processo histórico, afeta também o desenvolvimento da periodização.

Periodização refere-se a uma psicologia que aborda o estudo do desenvolvimento psíquico humano, desde o nascimento até a idade adulta, utilizando fases e assumindo que o desenvolvimento é um processo histórico-cultural, que se produz nas particularidades de cada cultura. Assim, não podemos considerar como algo universal e pré-estabelecido e natural, que ocorrerá da mesma forma com todos os indivíduos. Não é a idade cronológica que determinará o período do desenvolvimento psíquico, pois o psiquismo faz caminhos distintos em conteúdo, em forma e estrutura dos processos psíquicos em indivíduos diferentes também (PASQUALINI, 2013). Todos esses períodos passam por momentos de crise, como deixa explícito Pasqualini:

A transição a um novo período, que representa um salto qualitativo, configura um momento crítico do desenvolvimento. É o momento da revolução em que mudanças bruscas se processam em um curto período de tempo, produzindo uma reorganização do psiquismo (PASQUALINI, 2013, p. 81). 
Neste momento, não iremos elucidar sobre todas as fases, mas nos debruçaremos sobre a Infância, no período Escolar de 6 a 10 anos, no qual contém como atividade dominante a "atividade de estudo", com ênfase intelectual-cognitivo e na relação criança e objeto social.

A atividade de estudo na idade escolar (6-7 anos a 10 anos) para Vigotski é porque, ao entrar na escola, a criança sofre profundas transformações no desenvolvimento infantil. A atividade escolar não proporciona apenas a sistematização de conhecimentos, mas também produz desenvolvimento psicológico na medida em que atua na Zona de Desenvolvimento Proximal, e a atividade de estudo permite essa apropriação.

As crianças ingressam na escola com a expectativa de aprender a ler e a escrever, por isso é socialmente valorizada e produz interesse social. Uma das mudanças produzidas pela atividade de estudo é justamente a formação da necessidade cognitiva e dos motivos correspondentes, já que estabelece com os professores uma relação de um círculo íntimo de seus contatos e passa a controlar seu comportamento, e a reconstruir o movimento dialético do pensamento, desenvolvendo também a ascensão do pensamento abstrato ao concreto, isso representa o salto qualitativo do desenvolvimento humano (ASBAHR, 2016).

Na transição entre o período pré-escolar para a idade escolar dentro da infância não existem apenas deveres para com os pais e os professores, mas há, objetivamente, obrigações para com a sociedade (LEONTIEV, 2010). E em consequência disso, tudo aquilo que a criança atribui um novo significado, mais rapidamente seu psíquico se reorganiza e modifica.

O estudo é mediado por todos adultos que cercam a criança nesse momento, já que são observáveis mudanças que acontecem mesmo dentro da família, como por exemplo: os adultos questionam sobre a escola, reafirmando a ela seu dever e sua responsabilidade em relação à escola e a importância dela na sua vida (FACCI, 2004).

Muda então a posição social da criança: "é exigido que o estudante em formação assuma novas obrigações, organize seu trabalho de forma sistemática, assuma novos deveres e direitos" (ASBAHR, 2016, p.173). Isso não se desenvolve naturalmente, por isso a escola também atua como formadora da postura da criança como estudante, estabelecendo motivos para o estudo, mesmo que inicialmente sejam motivos afetivos, depois dos resultados obtidos, esse motivo passa a ser aprender e é incluído em sua prática social com um sentido pessoal.

$\mathrm{Na}$ atividade de estudo ocorrem apropriações de novos conhecimentos, onde o principal objetivo é o ensino. A criança compreende essa importância e passa a atribuir significado e sentido a aprendizagem despertando seu interesse, pois é a sua necessidade 
nesse momento. Afinal, isso despertará novas relações em seu contexto social, pois se torna consciente das relações que mantém e essa conscientização possibilita mudanças futuras dessa atividade, fazendo surgir novos motivos e reiterando ações anteriores.

O professor deve criar situações para proporcionar aos estudantes autonomia nas tarefas de estudo e na capacidade de estudar. Deste modo "a atividade de ensino do professor e a atividade de estudo dos educandos devem constituir-se como unidade dialética" (ASBAHR, 2016, p. 187). Portanto, nesse processo o estudante transforma suas relações com seus objetos de estudo, consigo mesmo e com as outras pessoas, tornando-se sujeito da sua atividade, desenvolvendo a consciência e a formação do pensamento teórico.

O desenvolvimento infantil é um espiral dialético e por isso paira uma dúvida sobre o que ensinar para as crianças e como ensiná-las, para isso é preciso compreender quem é essa criança em cada período de desenvolvimento e analisar a dinâmica entre a situação social de desenvolvimento, a atividade dominante e as novas formações e considerar a ação do professor para criar motivos para a atividade de estudo. Frente a isso destaca:

As verdadeiras potencialidades do ensino e da educação para impulsionar o desenvolvimento são reveladas quando seu conteúdo, que o meio de organização da atividade reprodutiva da criança, corresponde por completo às peculiaridades psicológicas, assim como às capacidades que são formadas com base nestas atividades. O papel desenvolvimental do ensino e da educação se reduz ao reduzido ao mínimo, caso as atividades não estejam de acordo com estas distintas características ou mesmo contrapondo-as (DAVIDOV, 1998, p. 241).

\section{Procedimentos metodológicos}

A temática em questão foi escolhida por solicitação da Secretária de Educação do Município de Marilena-PR. Esta enfatizou sua preocupação atual referente ao grande número de crianças com dificuldades de aprendizagem e tinha interesse de aprender um pouco mais sobre o assunto e as contribuições da Psicologia.

Na impossibilidade da análise de um universo maior de crianças, em razão do tempo disponível para a pesquisa, selecionamos duas crianças que se encontram no período do desenvolvimento compreendido por Elkonin como a Infância, cuja atividade dominante é a atividade de estudo.

As duas crianças selecionadas estudam na rede municipal de ensino e serão mencionadas neste trabalho com os seguintes pseudônimos: "Léo" (07 anos) e "Vick" (10 anos). Importante destacar que já era realizado um trabalho psicopedagógico com estas 
crianças no Centro de Referência em Assistência Social - CRAS do município de Marilena $\mathrm{PR}$, com intervenções da psicopedagoga que atende as Escolas Municipais, devido às dificuldades de aprendizagem que esses alunos possuem em relação à idade e a série em que se encontram.

Léo é uma criança de 07 anos, do sexo masculino, que está no segundo ano do Ensino Fundamental do município de Marilena - PR. Foi encaminhado para avaliação psicopedagógica por solicitação da escola, diante de suas dificuldades de aprendizagem, sobretudo na área de língua portuguesa. Vick é uma criança de 10 anos, do sexo masculino, está no terceiro ano do Ensino Fundamental, do mesmo município. As queixas de dificuldades de aprendizagem de Vick surgiram no segundo ano do Ensino Fundamental e, ao passar para o terceiro, ficou retido por dois anos. Vick apresenta dificuldade na área da língua portuguesa e matemática. É importante ressaltar que ao findar a avaliação, a psicopedagoga do município costuma fazer uma devolutiva para a direção da escola, a professora e os pais do aluno, apresentando sugestões de intervenções e os encaminhamentos necessários para cada criança.

$\mathrm{O}$ atendimento foi desenvolvido em dois lugares diferentes: o aluno Vick foi atendido no CRAS da cidade de Marilena e o aluno Léo foi atendido na própria escola em que estuda, em uma sala separada, ambos foram sozinhos, apenas acompanhado de um estojo.

Para a coleta de dados a pesquisa utilizou o método clínico, inicialmente utilizado por Piaget como um método de conversar com as crianças, para tentar aprender a sequência dos seus pensamentos. Trata-se de um método baseado em um diálogo sistemático com a criança, de acordo com o que a criança vai fazendo ou respondendo. É um procedimento de entrevistas com as crianças, com coleta de dados e análise de dados, acompanhando o pensamento da criança, com intervenção sistemática, elaborando novas perguntas conforme as respostas recebidas. A intenção é compreender o nível de desenvolvimento da criança de forma flexível e espontânea (TRIVIÑOS, 1987).

O procedimento com a criança Léo foi realizado no período do dia 12 de março de 2019 ao dia 11 de abril de 2019, e da criança Vick, no período do dia 11 de março de 2019 ao dia 15 de abril de 2019.

A metodologia utilizada incluiu observação dos alunos e do processo com intervenções das duas pesquisadoras nos momentos oportunos para analisar os desenhos e a escrita, e assim compreender o que eram capazes de fazer sozinhos e o que eram capazes de fazer após uma intervenção (ZDP). Trata-se de uma pesquisa qualitativa, pois as pesquisadoras agregam em sua investigação conceitos culturais já apropriados pelas mesmas e 
a interpretação e a busca de significados é realizada relacionada às concepções de homem e de mundo (TRIVINÕS, 1987).

O procedimento iniciou com a solicitação de que a criança desenhasse "o que é escola", o que é "não escola", e posteriormente, "o que é casa" e o que é "não casa". Foi solicitado à criança que iniciasse desenhando o "que é escola" e, enquanto desenhavam, foi pedido que escrevessem ao lado o nome do que estavam desenhando. Na sequência, a criança foi orientada a desenhar, o que é "não escola", esse comando teve dificuldade de compreensão por ambos, então foi feita intervenção já na hora da explicação. Depois para compreender melhor sua rotina a criança desenhou "o que é casa" e o que é "não casa" nessa mesma ordem, posteriormente a criança nomeou os seus desenhos, e depois questionado se eles queriam pintar seus desenhos.

Após isso, e para finalizar a pesquisa, com base na capacidade da linguagem escrita de cada criança, foi solicitado que escrevessem um texto sobre "o trajeto da sua casa até a escola”. Enquanto escreviam, eram questionados oralmente sobre como iam para escola, com quem, o que faziam quando chegavam a suas casas. Essa etapa foi importante para analisar o contexto social e cultural da criança, e o quanto isso influenciou em seus desenhos.

Portanto o estudo focou a aquisição da linguagem escrita e as possibilidades de intervenção do pesquisador na ZDP. A análise dos dados foi realizada a partir do grafismo e do conteúdo. Foram construídos os seguintes indicadores da análise gráfica: preensão-força; habilidade espacial de representação; cores; precisão/riqueza de detalhes; planejamento e proporção/lógica. Para a análise conceitual os indicadores foram os seguintes: internalização, atividade voluntária, sentido e significado e mediação.

\section{Apresentação e análise dos dados}

Para apresentar os dados da pesquisa optamos por analisar por dois aspectos: primeiramente pela análise gráfica, considerando que é o primeiro domínio que as crianças desenvolvem: os rabiscos mecânicos. Segundo Vigotski (1991), os traços constituem toda a representação do mundo concreto e, no primeiro momento, as crianças desenham aquilo que elas conhecem, fase preliminar no desenvolvimento da linguagem escrita. Posteriormente, passaremos à análise conceitual com base em Coelho (2011), para compreender a ligação existente entre a função simbólica e o desenvolvimento da linguagem escrita, confirmando que existe uma linha histórica gradual. Através disso, a linguagem escrita passa a ser percebida da mesma forma que a linguagem falada e, principalmente, nesse momento essas 
análises foram feitas em relação a aquisição da linguagem escrita nas crianças de 6-10 anos do município de Marilena-PR. É importante mencionar que esta pesquisa entende que os aspectos gráficos e conceituais estão intimamente relacionados e se desenvolvem dialeticamente no percurso da aprendizagem da criança. A opção por categorizá-los constitui apenas uma forma de apresentação textual e melhor compreensão das análises.

5.1 Análise gráfica: pré-história da linguagem escrita

Figura 1 - Atividade desenvolvida pelo aluno "Léo"

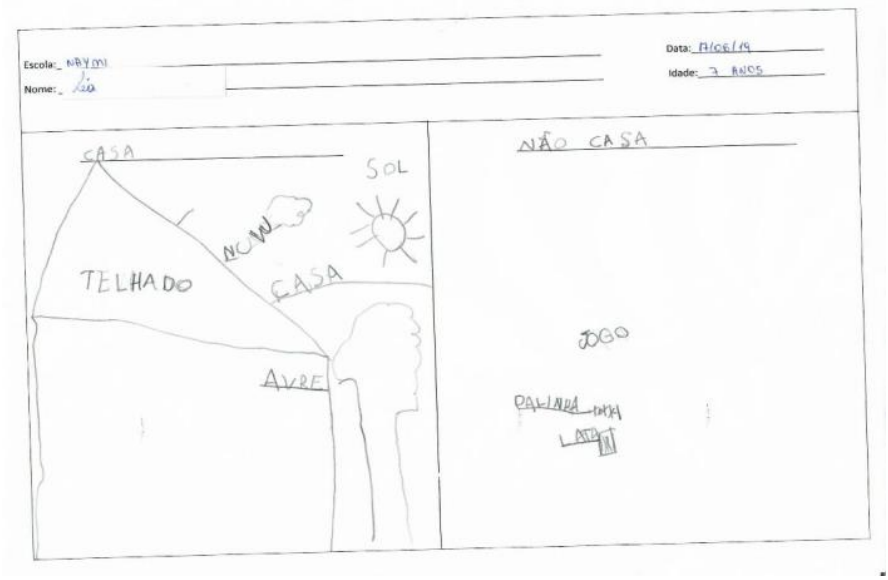

Fonte: As autoras, 17 de junho de 2019.

Figura 2 - Atividade desenvolvida pelo aluno "Léo"

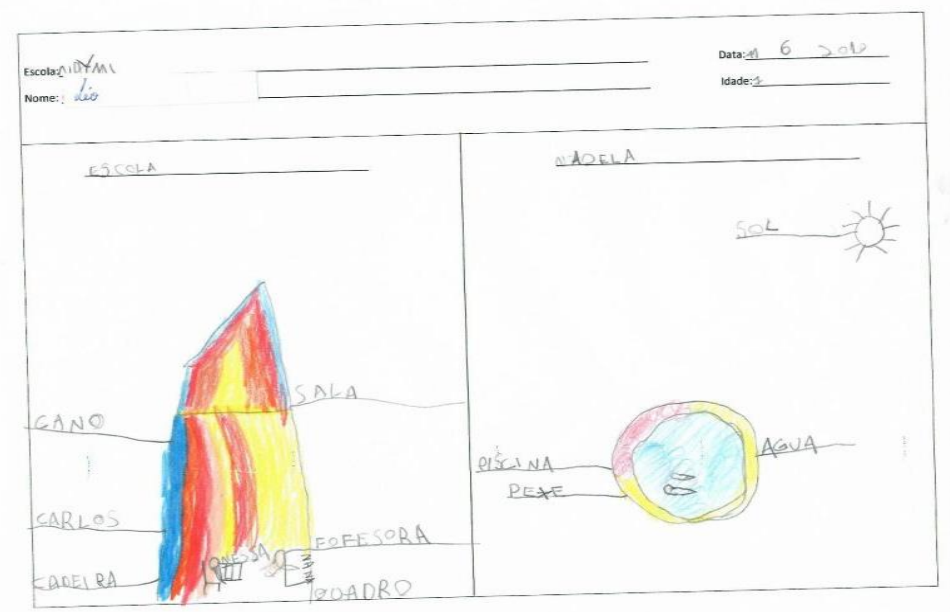

Fonte: As autoras, 17 de junho de 2019. 
Figura 3 - Atividade desenvolvida pelo aluno "Vick"

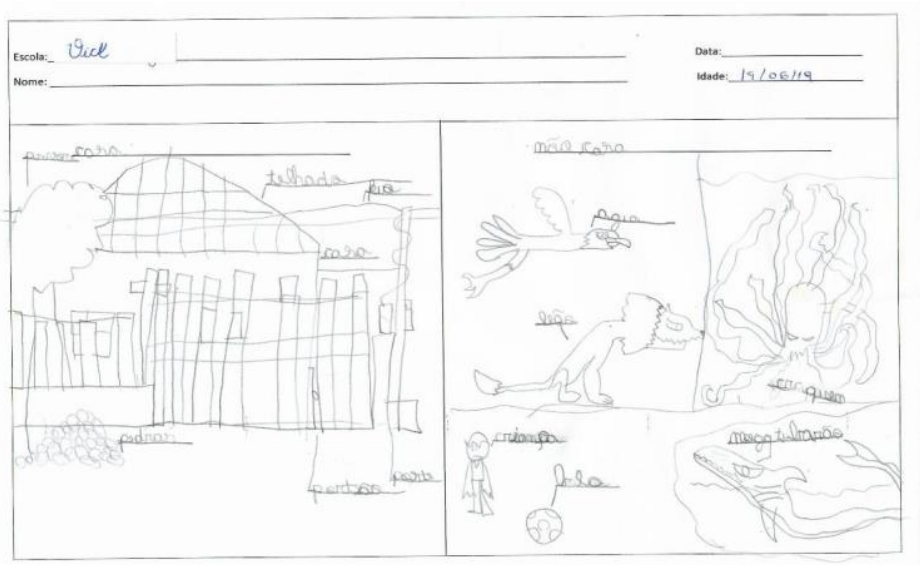

Fonte: As autoras, 14 de junho de 2019.

Figura 4 - Atividade desenvolvida pelo aluno "Vick"

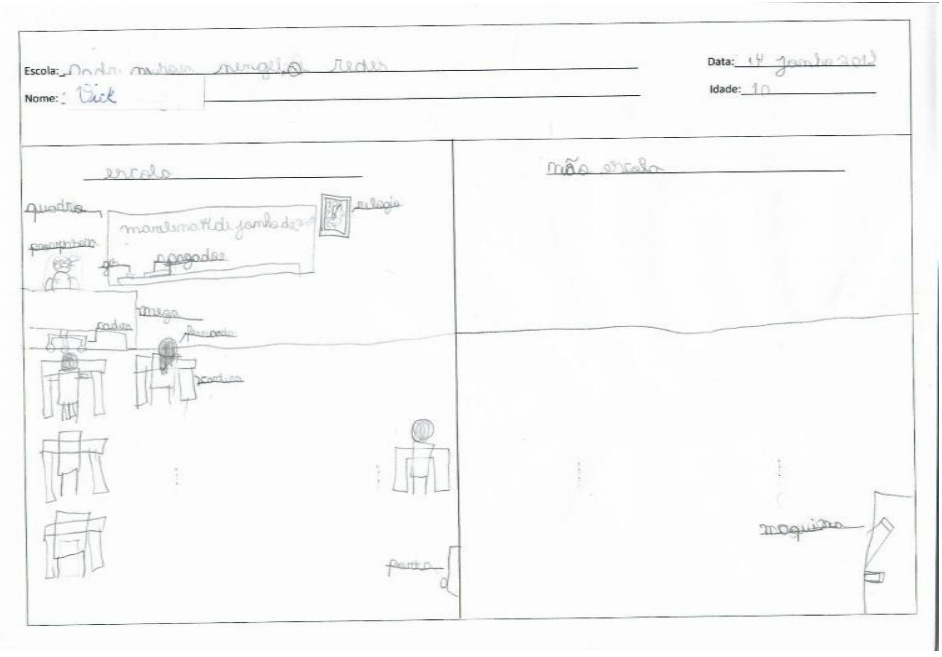

Fonte: As autoras, 14 de junho de 2019.

Em relação à preensão - força, destacamos que o aluno Léo possui um nível de força maior que o aluno Vick, pois o aluno Léo evidenciou isso na pintura realizada no colorido onde dispôs da força aplicada ao lápis para pintar. Já o aluno Vick, em seus desenhos optou por não colorir. Entretanto, a menor preensão em seu desenho - é possível notar através da pintura com o próprio lápis de escrever no cabelo das pessoas -, pode estar relacionada à idade do aluno Léo (07 anos) não possibilita ainda grade capacidade de representação, portanto, possui menos riqueza nos detalhes e mais preensão. Por sua vez, o aluno Vick (10 anos) apresenta essa preensão menor por ter internalizado e estar ligado mais aos detalhes, sua capacidade de transposição gráfica ser maior.

A habilidade espacial de representação indica a capacidade de realizar o desenho de acordo com o espaço na folha de papel. Comparando os dois alunos, o aluno Léo (07 anos) 
apresentou menor noção de espaço que o aluno Vick (10 anos), por ainda não ter internalizado o sentido e a riqueza de detalhes, mesmo que ele tenha conhecimento desses detalhes, sua capacidade de representá-los é menor. O aluno Vick tem maior capacidade do uso do espaço e consegue transpor isso ao papel, com maior riqueza de detalhes e aproveitando o espaço para desenhar aquilo que é mais significativo para ele.

Em relação a cores, o aluno Léo (07 anos) optou por colorir um desenho, enquanto o aluno Vick (10 anos), optou por não colorir. O aluno Léo coloriu ambos os desenhos solicitados ("o que é escola" e o que é "não escola"): por se encontrar na fase da atividade de estudo, atribui maior sentido à escola e ao seu momento de aprendizado do que em relação ao que é "casa" e "não casa". Enquanto isso, o aluno Vick, apesar de ser mais velho, se negou a pintar, seu desenho representou apenas partes significativas a ele e demonstrava-se ansioso para terminar logo.

A precisão/riqueza de detalhes é um tópico interessante de analisar, pois o aluno Léo (07 anos) apresentou menor riqueza de detalhes em comparação com o aluno Vick (10 anos). Podemos atribuir isso à idade e a capacidade de transpor para o desenho o que observa na realidade concreta. Léo conhece os detalhes, mas tem menor capacidade de fazer a representação simbólica. Assim, ele desenhou apenas ele e a professora em sala de aula, o que demostra que o aspecto afetivo do sentido que este atribui à sua relação com a professora. $\mathrm{O}$ aluno Vick apresentou maior riqueza de detalhes, desenhando também a professora, com suas características pessoas reais, e os colegas de sala com os quais tem maior afinidade. Ou seja, seu desenho rico em detalhes foi baseado naquilo que tem mais sentido e significado pessoal para sua vida.

Em relação ao planejamento do desenho, era para desenhar "o que é escola" e o que é "não escola", assim como também "o que é casa" e o que é "não casa". Uma observação bem interessante referente a isso é que em nenhum momento foi solicitado para desenhar a sala de aula no título "o que é escola" e, apesar disso, os dois alunos desenharam a sala de aula, mesmo não estando presentes na sala de aula naquele momento. Isso prova que ambos estão no período da atividade de estudo como atividade dominante em seu desenvolvimento e o que tem de maior sentido e significado para eles na escola é a sala de aula e a figura da professora. Ambos desenharam este espaço com a presença da professora - mesmo com diferentes níveis de detalhamento -, local onde ocorre a mediação e internalização do conhecimento.

A proporção/lógica do desenho também está ligada ao nível de desenvolvimento de ambos os alunos, apresentando a predominância da representação pictográfica: desenham como forma de escrita, pois a escrita de ambos não se apresenta totalmente letrada. Mesmo 
assim, o aluno Vick (10 anos) tem maior capacidade de proporção correta no desenho, por estar com os conceitos mais internalizados. Vick representou desenhos que estavam na sua imaginação (abstração) e não no real e concreto, provando que sua capacidade de representação gráfica é mais evoluída que de Léo (7 anos), que desenhou apenas o que é real e já viu em seu mundo concreto.

5.2 Análise conceitual: mediação e transição para a linguagem escrita

Figura 5 - Atividade desenvolvida pelo aluno "Léo"

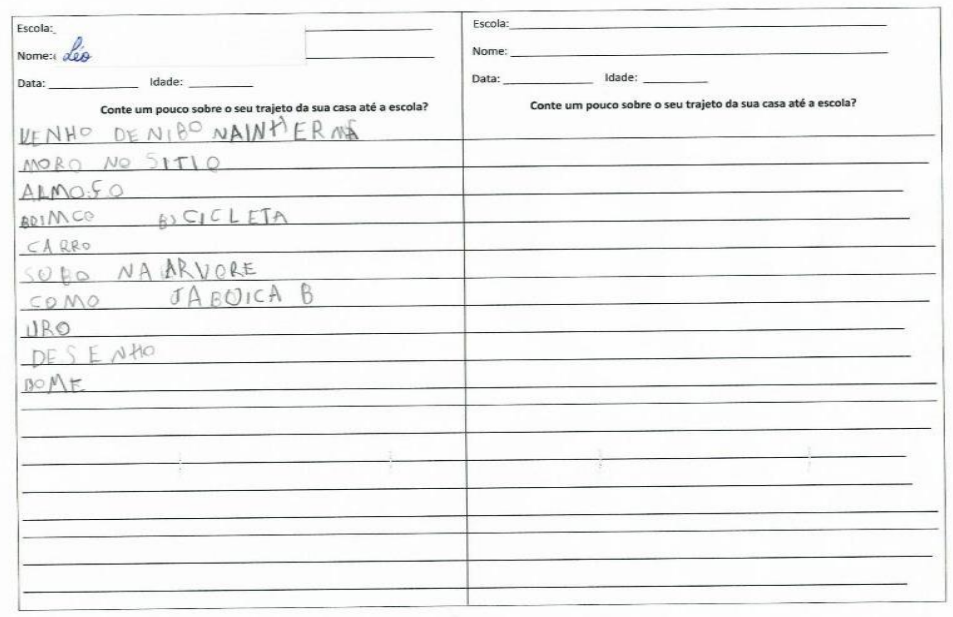

Fonte: As autoras, 17 de junho de 2019.

Figura 6 - Atividade desenvolvida pelo aluno "Vick"

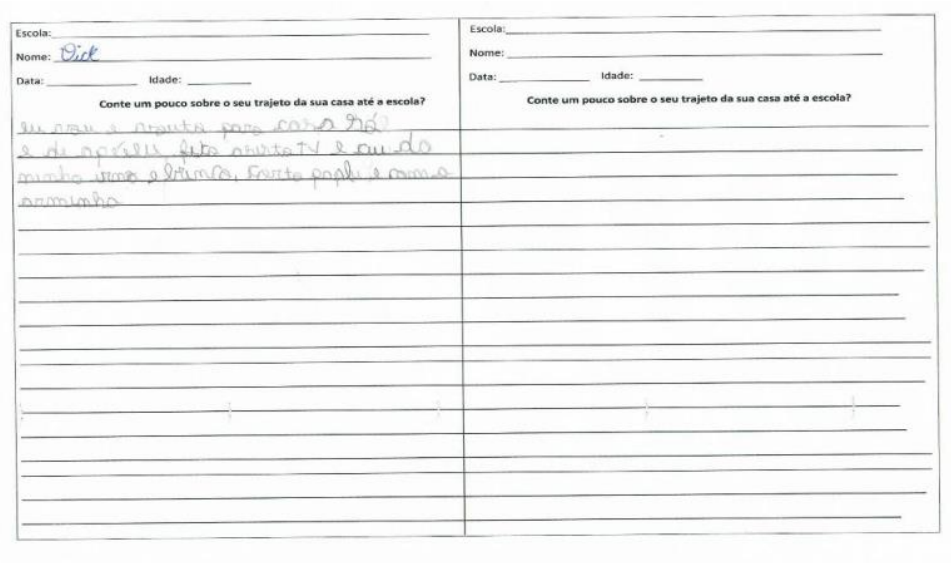

Fonte: As autoras, 14 de junho de 2019.

As crianças analisadas estão no processo de transição da linguagem falada para a linguagem escrita, ou seja, não internalizaram totalmente a linguagem escrita. Assim, como exemplo, o aluno Vick (10 anos), foi desenhando e contando tudo o que estava fazendo. Em 
sua linguagem falada apresentou bastante detalhe assim como no desenho, como uma forma que ele encontrou para que o outro entendesse o que ele estava comunicando no desenho. Enquanto isso, o aluno Léo (7 anos) teve muita dificuldade para compreender os comandos e por isso precisou de mediação em todas as etapas, tanto no desenho, quanto na linguagem falada e linguagem escrita. Assim, Léo não detalhou o que estava desenhando e muitas vezes esquecia o que tinha desenhado, como podemos ver em sua fala:

Pesquisadora em relação a um desenho: O que é isso que você desenhou em cima da mesa?

Léo: Cabeça?

Pesquisadora: Tente lembrar.

Léo: Caderno.

Isso mostra que o aluno teve dificuldade na abstração do pensamento, de ler o que ele tinha desenhado.

No processo de internalização (interpsicológico para o intrapsicológico), primeiro a criança aprende a se comunicar na linguagem falada com o mundo social e, através dessa comunicação, internaliza o conhecimento para, posteriormente, desenvolver a linguagem escrita. Quando a internalização da prática coletiva ocorre a criança consegue ser independente. Com base nisso, as crianças analisadas estão no processo de internalização, pois tanto Vick quanto Léo precisam de mediação para nomear através da escrita os desenhos. O mesmo pode-se dizer sobre a relação ao trajeto casa-escola e escola-casa, pois ambos tiveram mais facilidade para expor pela linguagem falada o que faziam no trajeto da escola até a sua casa. Porém, no momento da escrita por não estar ainda totalmente internalizada, não conseguiram formar frases sobre isso, apenas palavras com a mediação das pesquisadoras.

A atenção voluntária relacionada aos motivos é outra categoria a ser analisada, pois por meio da internalização que se origina as funções psicológicas superiores, tais como o pensamento, a atenção voluntária e o controle consciente do comportamento, funções que possuem relação direta com a consciência na prática escolar. É a atenção voluntária que leva a criança à atividade de estudo. Percebemos que o aluno Léo (7 anos) apresenta desenvolvimento mais esperado da atenção voluntária relacionada à sua idade cronológica. Em relação ao aluno Vick (10 anos), embora mais velho que Léo, apresentou menor nível de concentração e interesse na atividade proposta. Isso nos leva a supor que, provavelmente, Vick não desenvolveu motivos que o impulsionasse a aprender, apesar de estar também na fase da atividade de estudo. 
O sentido e significado é fator importante na aprendizagem e na internalização para os alunos. Para isso, o mediador tem papel fundamental para tornar o processo mais significativo para as crianças. Isso é fundamental para que estas desenvolvam a compreensão abstrata e o interesse pelo conhecimento científico, superando gradativamente a fase préescrita. As crianças observadas apresentaram a escrita simbólica, ou seja, usam a escrita em sua função social, é através da presença do outro que o sujeito estabelece relações com objetos dados ao seu conhecimento.

Supomos que a ordem escolhida para o procedimento das entrevistas tenha influenciado nos resultados da escrita simbólica. Como primeiro foi pedido para os alunos desenharem e depois escreverem, percebemos que a qualidade do desenho foi bem maior que a qualidade da escrita. Isso pode ter ocorrido pelo fato dos alunos sentirem mais prazer e segurança em desenhar, e pelo próprio sentido que as crianças trouxeram para o desenho.

A escrita gera maior insegurança, já que a criança precisa dar um salto qualitativo da Zona de Desenvolvimento Real para a Zona de Desenvolvimento Potencial e isso só é possível quando a linguagem escrita é internalizada significativamente.

As duas crianças estão em processo de desenvolvimento da linguagem escrita, sendo que no aluno Léo (7 anos) percebe-se que, mesmo na construção do desenho ele apresentava dificuldade em encontrar sentido. Quando a pesquisadora perguntou se ele havia desenhado toda a sua escola ou só a sua sala de aula, ele foi enfático em responder "não sei". Isso interfere em sua comunicação e transferência para a escrita.

Por fim, para que tudo isso aconteça é importante outra categoria, a mediação. Como afirma Vygostky, é por meio do adulto, do contexto em que está inserida que a criança consegue aprender, a internalizar, a desenvolver sua capacidade de abstração e encontrar o significado da atividade de estudo. Ambos os alunos precisaram de constante mediação do adulto durante a construção da linguagem escrita, apesar das idades serem diferentes.

Com o aluno Léo (7 anos), um dos momentos que ocorreram mediação foi referente ao desenho da casa:

Pesquisadora: o que tem em cima da casa?

Léo: telhado.

Pesquisadora: pode escrever então.

Léo: te, o T e o E, lha, o N.

A pesquisadora então fez a mediação: lha, se pôr o $\mathrm{N}$ fica tenado, que outra letra que usa para fazer o lha?

Léo: o $\mathrm{H}$.

Pesquisadora: isso mesmo, e antes do $\mathrm{H}$ tem que letra?

Léo: o A. 
Pesquisadora: lha, que letra tem?

Léo: o Q?

Pesquisadora: lha? (Enfatizando bem o som).

Léo: o L.

Pesquisadora: terminou de escrever telhado? O que está faltando?

Léo: o D e o O.

Percebe-se aqui que, sozinho o aluno não conseguiu formar a palavra, precisou da intervenção do adulto para que ele conseguisse.

Com o aluno Vick também ocorreram muitos momentos de mediação e para exemplificar trouxemos a seguinte intervenção:

Pesquisadora: pode escrever quadro.

Vick: não sei escrever.

Pesquisadora pergunta então se ele sabe escrever QUA.

Vick: Q R A?

Pesquisadora: QUAAA, que som sai depois do U? Q U e o?

Vick: N?

Pesquisadora: QUAAA...

Vick: Só tem três letras fazem esse som, M L e N.

Pesquisadora questiona e ele diz que sim, somente essas letras. Pesquisadora: vou dar uma dica é Q U e a primeira letra do alfabeto.

Vick: A?

A pesquisadora concorda

Vick: é que eu esqueci que depois do Q precisa do U para fazer o som.

Portanto depois que foi realizada a mediação o aluno se lembrou de conceitos já internalizados da linguagem escrita.

\section{Considerações finais}

Ao fim dessa pesquisa, podemos concluir, que com este estudo foi possível compreender o processo de apropriação da linguagem escrita no desenvolvimento do psiquismo mediante ao processo discursivo, que deve ser internalizado através da utilização da Zona de Desenvolvimento Proximal, e entendemos que o desenvolvimento ocorre nas interações sociais, na mediação entre professores e alunos. Considerando a periodização e a atividade de estudo em que as crianças se encontram, percebemos que a importância e sentido que cada criança atribui à aprendizagem depende do contexto histórico-cultural em que está inserida. 
Além disso, a apropriação da linguagem escrita é um processo dialético e ocorre gradualmente e isso é possível por meio da linguagem falada que atua mediando esse processo. Sendo assim, ambos os alunos ainda dependem da linguagem falada para explicar a sua escrita, ou seja, ainda não internalizaram por inteiro a escrita no processo discursivo. Portanto, a escrita ainda não é o Nível de Desenvolvimento Real dessas crianças, pois não conseguem realizar sozinhas as escritas convencionais. Apesar disso, conseguem realizar com a mediação de alguém, que se refere ao Nível de Desenvolvimento Potencial, ou seja, elas alcançaram os objetivos de escrita por meio da mediação das pesquisadoras durante a pesquisa.

Em relação à periodização, embora em níveis diferentes, ambos os alunos estão na fase escolar, tendo como atividade dominante a atividade de estudo. Isso se comprova não apenas pela idade cronológica, mas porque quando os alunos foram questionados sobre "o que é escola", ambos desenharam a sala de aula. O que isso tem a ver? Bom, eles poderiam ter desenhado qualquer parte da escola, mas desenharam o espaço onde ocorre a mediação, sem intervenção das pesquisadoras, ou seja, para eles a sala de aula contém significado internalizado e sentido pessoal positivo.

\section{REFERÊNCIAS}

ASBAHR, Flávia da Silva Ferreira. Idade escolar e atividade de estudo: educação, ensino e apropriação dos sistemas conceituais. In: MARTINS; Ligia Márcia; ABRANGES Ângelo Antônio; FACCI, Marilda Gonçalves Dias. Periodização Histórico-Cultural do Desenvolvimento Psíquico: do nascimento à velhice. São Paulo: Autores Associados, 2016.

BAMPI, Maria Alice Moreira. O método clínico experimental de Jean Piaget como referência para o conhecimento do pensamento infantil na avaliação psicopedagógica. 2006. 104f. Dissertação (Mestrado em Psicopedagogia) - Programa de Pós-Graduação da Universidade do Sul de Santa Catarina, Florianópolis, SC.

COELHO, Sônia Maria. Conteúdo e didática de alfabetização: a alfabetização na perspectiva histórico-cultural. UNESP. Volume 2. São Paulo: Cultura acadêmica, 2011.

DAVIDOV, V. V. Problemas do ensino desenvolvimental: a experiência da pesquisa teórica e experimental na Psicologia. Tradução: Beatrice Beach Szekely. Moscou: Progresso, 1998.

FACCI, Marilda Gonçalves Dias. A periodização do desenvolvimento psicológico individual na perspectiva de Leontiev, Elkonin e Vigotski. Cad. Cedes, Campinas, vol. 24, n. 62, p. 6481, abril 2004.

LEONTIEV, Alexei Nikolaevich. Uma contribuição à teoria do desenvolvimento da psique infantil. In: VIGOTSKI, Lev Semyonovich; LURIA, Alexander Romanovich; LEONTIEV, Alexei Nikolaevich. Linguagem, desenvolvimento e aprendizagem. $11^{\text {a }}$ edição. São Paulo: Ícone, 2010. 
OLIVEIRA, Marta Kohl. Vygotsky: aprendizagem e desenvolvimento; um processo sóciohistórico. 1. Ed. São Paulo: Scipione, 2009.

PASQUALINI, Juliana Campregher. A teoria histórico-cultural da periodização do desenvolvimento psíquico como expressão do método materialista dialético. In: MARTINS; Ligia Márcia; ABRANGES, Ângelo Antônio; FACCI, Marilda Gonçalves Dias. Periodização Histórico-Cultural do Desenvolvimento Psíquico: do nascimento à velhice. São Paulo: Autores Associados, 2016.

PASQUALINI, Juliana Campregher; EIDT, Nadia Mara. Periodização do desenvolvimento infantil e ações educativas. In: PASQUALINI, Juliana Campregher; TSUHAKO, Yaeki Nakadakari (Orgs.). Proposta pedagógica para a Educação Infantil do Sistema Municipal de Ensino de Bauru - São Paulo. Volume 1. Bauru, 2016, v. 1.

PASQUALINI, Juliana Campregher. Periodização do desenvolvimento psíquico à luz da escola de Vigotski: a teoria histórico-cultural do desenvolvimento infantil e suas implicações pedagógicas. In: MARTINS; Ligia Márcia; ABRANGES, Ângelo Antônio; FACCI, Marilda Gonçalves Dias. Periodização Histórico-Cultural do Desenvolvimento Psíquico: do nascimento à velhice. São Paulo: Autores Associados, 2016.

PASQUALINI, Juliana Campregher. Periodização do desenvolvimento psíquico à luz da escola de Vigotski: a teoria histórico-cultural do desenvolvimento infantil e suas implicações pedagógicas. In: MARSIGLIA, Ana Carolina Galvão (Org.). Infância e Pedagogia HistóricoCrítica. Campinas: Autores Associados, 2013.

SAVIANI, Dermeval. Escola e Democracia. $42^{\circ}$ Ed. Campinas: Autores Associados, 2012.

TRIVIÑOS, Augusto Nibaldo Silva. Introdução à pesquisa em ciências sociais: a pesquisa qualitativa em educação. 1. ${ }^{a}$ Ed. São Paulo: Atlas, 1987.

TULESKI, Silvana Calvo; EIDT, Nadia Mara. A periodização do desenvolvimento psíquico atividade dominante e a formação das funções psíquicas superiores. In: MARTINS; Ligia Márcia; ABRANGES, Ângelo Antônio; FACCI, Marilda Gonçalves Dias. Periodização Histórico-Cultural do Desenvolvimento Psíquico: do nascimento à velhice. São Paulo: Autores Associados, 2016.

VIGOTSKI, Lev Semenovich. A formação social da mente: o desenvolvimento dos processos mentais superiores. Tradução de José Cipolla Neto et al. 4. ${ }^{a}$ Ed. São Paulo: Martins Fontes, 1991.

\footnotetext{
' Acadêmica do curso de graduação em Psicologia do Centro Universitário UniFatecie. Email: nayaalves4@gmail.com

ii Acadêmica do curso de graduação em Psicologia do Centro Universitário UniFatecie. Email: micaela.solera@hotmail.com

iii Doutora em Educação (FE/UNICAMP). Docente do curso de graduação em Psicologia do Centro Universitário UniFatecie. Email: deniseklsb@yahoo.com.br
} 